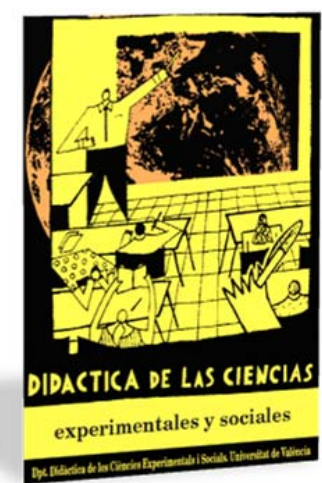

\title{
Análisis del discurso especista antropocéntrico en la Educación Secundaria Obligatoria
}

\section{Analysis of the anthropocentric speciesists speech in Compulsory Secondary Education}

DOI: $10.7203 / D C E S .34 .10944$

\author{
Patricia González Berruga \\ Universidad de Alicante \\ pgb19@alu.ua.es
}

\author{
Manuel Ángel González Berruga \\ Pontifica Universidad Católica de Ecuador Sede Esmeraldas - PUCESE \\ manuel.gonzalez@pucese.edu.ec
}

ORCID iD: http://orcid.org/0000-0001-7656-680X

\begin{abstract}
RESUMEN: La cuestión del bienestar animal, la liberación animal y el reconocimi ento de los animales como seres sintientes con derechos que protejan su integridad física y psicológica contrarios al discurso especista están cada vez más presentes en el discurso público desde provenientes de diferentes ámbitos. Aunque se observan aportaciones desde diferentes perspectivas y pretensiones, desde una perspectiva crítica, la consideración de los animales no ocupa un espacio relevante en el campo de los estudios sobre educación. El presente artículo muestra los resultados de una investigación cuyo objetivo es conocer el nivel del discurso especista en el currículo y los recursos didácticos utilizados en Educación Secundaria Obligatoria mediante la técnica del análisis de contenido.
\end{abstract}

PALABRAS CLAVE: ciencias naturales, especismo, antropocentrismo, análisis de documentos, currículo

ABstract: The animal welfare issue, animal liberation and the acknowledge of animal as sentient beings with rights which protect their physical and psychological integrity contrary on the speciesist speech are more present in the public speech from different fields. Although contributions from different perspectives and aspirations are noticed, from a critic perspective, the consideration of animals doesn't take up a relevant area in the educational research field. The present paper shows the results of a conducted research in order to know the speciesist speech level in the curriculum and educational resources used in Compulsory Secondary Education with content analysis technique.

KEYWORDS: natural sciencies, specism, anthropocentrism, content analysis, curriculum

Fecha de recepción: noviembre de 2017

Fecha de aceptación: abril de 2018 


\section{INTRODUCCIÓN}

La cuestión del bienestar anim al, la liberación anim al y el reconocimiento de los anim ales como seres sintientes con derechos que protejan su integridad física y psicológica contrarios al discurso especista son temas que están cada vez $\mathrm{m}$ ás presentes en el discurso público que surgen y señalan diferentes espacios de act uación: políticos, educativos, sociales, jurídicos, éticos, etc. Son muchas las organizacio nes, asociaciones, instituciones educativas, partidos políticos y $\mathrm{m}$ edios de comunicación, así como personas particulares que o bien prom ueven el desarrollo del discu rso a favor del bienestar animal o, por otro lado, adapta $\mathrm{n}$ el discurso a sus p rincipios e ideales (Men dez, 2014; Valencia y Vázquez, 2015). Aunque es difícil medir la repercusión de estos $m$ edios en la sociedad, podemos señalar algunos hitos que nos perm ite vislumbrar un cambio de tendencia en cuanto a la valoración del bienestar y la protección anim al como, por ejemplo, el incremento de le regulación a favor del bienestar anim al a ni vel europeo (Villalba, 2015, 2017) y en España (Ministerio de Medio Ambiente, Me dio Rural y Urbano, 2010; Minist erio de Agricultura y Pesca, Alimentación y Medio Am biente, 2017), el aum ento de apoyos al partido en favor del bienestar animal PACMA - que puede verse en https://pacma.es/resultados-elecciones.

Aunque la consideración de la naturaleza de los animales y su relación con el ser humano es una cuestión que ha sido visitada por diferentes autores en distin tos momentos histórico (Leyton, 2010) es a partir de los años 70 cuando han proliferado en el campo de la investigación y la producción científica estudios y ensayos relacionados con el bienes tar animal, los derechos de los animales o el especism o (Dorado y Horta, 2014). En relación al estudio de las cuestion es sobre bienestar animal dentro del currículo educat ivo se observan aportaciones desde diferentes perspectivas y pretensiones (Jukes y Chiuia, 2006; Mazas y Fernández, 2016). No obstante, desde una perspectiva crítica, la con sideración de los anim ales no ocupa un aspecto relevante en los estudios sobre educación (Pedersen, 2004).

\section{Planteamiento del problema}

Los cambios que se están produciendo a nivel social, en la relación entre seres hum anos y animales, y a nivel natural, donde el deterioro de lo s ecosistemas y la extinción de las especies por la acción del ser humano amenaza el equilibrio vital en el planeta tie rra (Ceballos y Ortega-Baes, 2011; Latouche y Harpagés, 2011; Ministerio de Agricultura, Alimentación y Medio Am biente, 2015), se entiende que es necesario introducir elem entos que eduquen en el antiespecismo y en e 1 bienestar y reconocimiento de los derechos de los animales en el currículo escolar para alcanzar una educación de calidad, $\mathrm{d}$ e justicia s ocial, y que pos ibilite el desarrollo de valores $\mathrm{m}$ orales que favorezcan la convivencia pacífica entre seres humanos, entre estos y el resto de seres v ivos, y sostenible con el medio natural que nos rodea.

La conceptualización de la palabra especismo no está exenta de controversia y crítica (Vázquez y Sánchez, 2017). La acepción escogida co mo punto de partida para el presente trabajo entiende el especismo como "la injustificada consideración de desventaja y tratamiento de aquellos que no están clasificados como pertenecientes a una o varias especi es particulares" (Horta, 2010, p. 244). Esta definición, como argumenta Vázquez y Sánchez (2017) está unida a la de antropocentrismo, entendido este como, en la relación entre animales y humanos, la primacía de los intereses de los seres humanos por encima de los intereses de los animales (Horta, 2009), aunque se pueden encontrar situaciones donde se produzca una situación de especismo pero no a favor del ser humano. Para el cometido del proyecto es im portante delimitar la idea de especis mo asociada al beneficio del ser hum ano donde los anim ales son entendidos como objetos destinados a satisfacer las necesidades humanas.

Una educación de calidad persigu e el desarro llo de contenidos rigurosos, contrastados científicamente, basados en hechos y realidad es comprobadas y que, a su vez, provoquen un estímulo cognitivo y despierten el interés por el mundo que rodea a los estudiantes (Hayes et al. 
2006). Una educación especista pu ede conducir al de sarrollo de ap rendizajes erróneos o a la generación de lagunas de conocim iento del área de Biología y Geología de contenidos básicos e imprescindibles para la formación de personas cultivadas capaces de comprender el medio en el que viven. Los déficits de conocimiento se encontrarían en aquellos contenidos que se relacionan con la consideración que el ser hum ano tiene de los anim ales como, por ejem plo, la interiorización de la falta de sintiencia de los animales, la creencia de que las vacas dan leche de $m$ anera natural sin necesidad de quedarse en cinta, la importancia de los animales para el equilibrio de los ecosistemas, la falta de conocim iento de las capacidades de los anim ales considerados "de granja" o como mascotas - o cóm o es el proceso de poner un huevo y la relación de este con la gallina.

Aprendizajes que, adquiridos de $m$ anera sesgada o errónea, contribuyen a la construcción de una visión del mundo irreal a la hora de relacionarse y actuar en el medio. Como aportan Jukes y Chiuia (2006) señalando la im portancia de cam biar la form a de experim entar con anim ales en ciencias naturales, el desarrollo de vías alternativas con lleva al desarrollo del pensam iento crítico y la resolución de problemas. La consideración de lo $\mathrm{s}$ animales como objetos supone una lim itación cognitiva que obstaculiza el acceso a un conocimiento de la realidad $\mathrm{m}$ ás profundo, diverso y amplio por la falta de reflexión y crítica sobre la relación entre el ser hum ano y los animales puesto que, desde una posición especista, es ta finaliza en el beneficio que los anim ales dan al ser humano. La ruptura de cier tas barreras cognitivas y culturales ha $\mathrm{p}$ ermitido que la cienc ia avance has ta posiciones hace unos años insospechadas como poner en discusión la conciencia de los animales o plantear un posicionamiento jurídico legal equi parable al de los hum anos (Low, 2012; Rowlands, 2016).

Un currículo de contenido antiespecista permite el desarrollo de valores morales y éticos que tiene como punto de partida la defensa de los intereses de los seres vivos oprim idos, en este caso, los animales. El especism o antropocéntrico es una form a de discrim inación basada en la consideración de la especie hum ana por encima del resto, argum ento con una lógica afín a otras formas de discrim inación como el racismo - la consideración de los intereses de una etnia por encima de la otra - o el sexism o - los intereses de un sexo por encima del otro. Una enseñanza basada en el especismo podría colocar al sujeto en una posición que permitiera proteger e imponer sus intereses frente a lo $\mathrm{s}$ que no reconoce con sus $\mathrm{m}$ ismos atributos. Una educación antiespecista debe dirigirse hacia la no discriminación por la causa que fuera y al reconocimiento de los intereses del resto de seres vivos con interé s por vivir. La cosificación de lo s animales conlleva a infligir un daño y un sufrim iento injustificado que se ha norm alizado como en el caso de la taurom aquia, las peleas de gallos o perros o la caza, lo que supone un "mal síntoma" que avisa de la posibilidad de infligir daño y sufrimiento contra el ser humano (Ortiz, 2014).

Otro aspecto a tener en cuenta es la introdu cción de los anim ales dentro de las relaciones sociales de los sujetos. Cada vez son $\mathrm{m}$ ás los animales registrados considerados de compañía que comparten espacios públicos y priv ados con las personas (Ministerio de Agricultura, Alimentación y Medio A mbiente, 2015) produciéndose una relación de beneficio m utuo (Zamarra, 2002) generando vínculos más allá de la simple cosificación de los animales (Gómez, Atehortua y Orozco, 2007; Hugues, Álvarez, Lerdón, Mendoza, Castel o y Domínguez, 2014) considerándolos, incluso, como miembros de la fa milia (Díaz, 2015; González y Landero, 2011). El des arrollo de u na sociedad para la $\mathrm{p}$ az erigida en el principio d e justicia social tiene que tener en cuenta a los animales dentro del en tramado de relaciones social. Esto se traduce en la provisión de una educación pública destinada al reco nocimiento de los animales como seres vivos con sus propias necesidades e intereses. La falta de reconocim iento de los animales puede conducir al desarrollo de sentimiento de injusticia, inmoralidad y desprecio hacia los animales que perjudiquen las relaciones de convivencia en comunidad entre personas.

La etapa de educación secundaria supone un proceso de desarrollo cognitivo y moral donde se construye la identidad del sujeto en su re lación con el medio. En este proceso, los estudiantes interiorizan una serie de concep tos asociados a valores $m$ orales que van construyendo su realidad 
como el significado d e empatía, sensibilidad o com pasión. La capacidad de respuesta a los estímulos sociales dependerá de la educación emoci onal recibida, esto es, de la ad ecuada relación entre las reacciones em otivas percibidas y la c onceptualización de las mism as que, desarrollada a través de una discusión ética, permitirá afrontar de manera eficaz la complejidad de las situaciones vitales experimentadas en el desarrollo de habilid ades psicológicas y emoci onales y la inte racción con el m edio que le rodea (Jukes y Chiuia ，2006; Mayer y Salovey, 1997). La for ma de discriminación y opresión desde el especism o se in serta en el currícu lo oculto de la form ación reglada desarrollando dinám icas y estrategias que se dirigen al establecim iento de relaciones de control y poder similares a otras formas de segregación (Pedersen, 2004).

\section{Metodología de LA INVESTigACión}

El proyecto de investigación surge con la idea de conocer el nivel del discurso especista antropocéntrico del currículo en la etapa de la Educación Secundaria Obligatoria (ESO). Se adopta un enfoque cualitativo (McMillan y Schum acher, 2005) a través del an álisis de contenido (Fernández, 2002). Para ello se tiene en cuenta tres niveles de anál isis: a nivel macro, el currículo prescrito a nivel nacional y en cada Comunidad Autónoma; a nivel meso, el currículo concretado en el departamento didáctico; y a nive 1 micro, los contenidos trabajados en el aula por los estudiantes. Los documentos objeto de análisis son las unidades di dácticas de libros de texto y recursos en línea utilizados para el aprendizaje desde el área de Biología y Geología, las programaciones didácticas de tres departam entos de Biología y Geología de tres institutos de la Comunidad de Castilla La Mancha a las que se tuvo acceso, el currícu lo de Biología y Geo logía para la ESO a nivel autonómico de Castilla La Mancha y a nivel nacional a través de la concreción de los contenidos del currículo establecido por la LOMCE en el Real Decreto 1105/2014. En cad a recurso didáctico se seleccionan las unidades didáctic as o tem as donde se trata el est udio de los anim ales de manera particular o en su relación con el medio natural y social. Para el acceso a estos recurs os se consultó con profesores y profes ionales de la educación de las ciu dades de Alican te y Albacete po $r$ la cercanía con el investigador principal.

\subsection{Tabla de indicadores}

El análisis de conten ido se rea liza a partir de una tabla de indicadores ad hoc donde se representan 4 niveles de especism o: "Nulo" representa un conteni do que no se refiere al especismo antropocéntrico; "Alto" representa un contenido que se refiere a lo s animales como si de objetos materiales se trataran, no se tiene en cuenta su capacid ad de sufrimiento y disfrute de la vida ni la relación que guarda con el medio natural o social; "Medio" representa un contenido que reconoce a los animales como objetos por el beneficio que aporta al ser humano en el medio natural o social; $y$ "Bajo" representa un contenido que reconoce a lo s animales como seres vivos con derechos que protejan su integridad física y psicológica por su condición de existir en el m edio natural o social. Los elementos a analizar del cada uno de los libros de te xto y recursos web son los Objetivos/Competencias, Contenidos, Actividades, Criterios de Evaluación/Estándares de aprendizaje e Imágenes. (Tabla 1). 


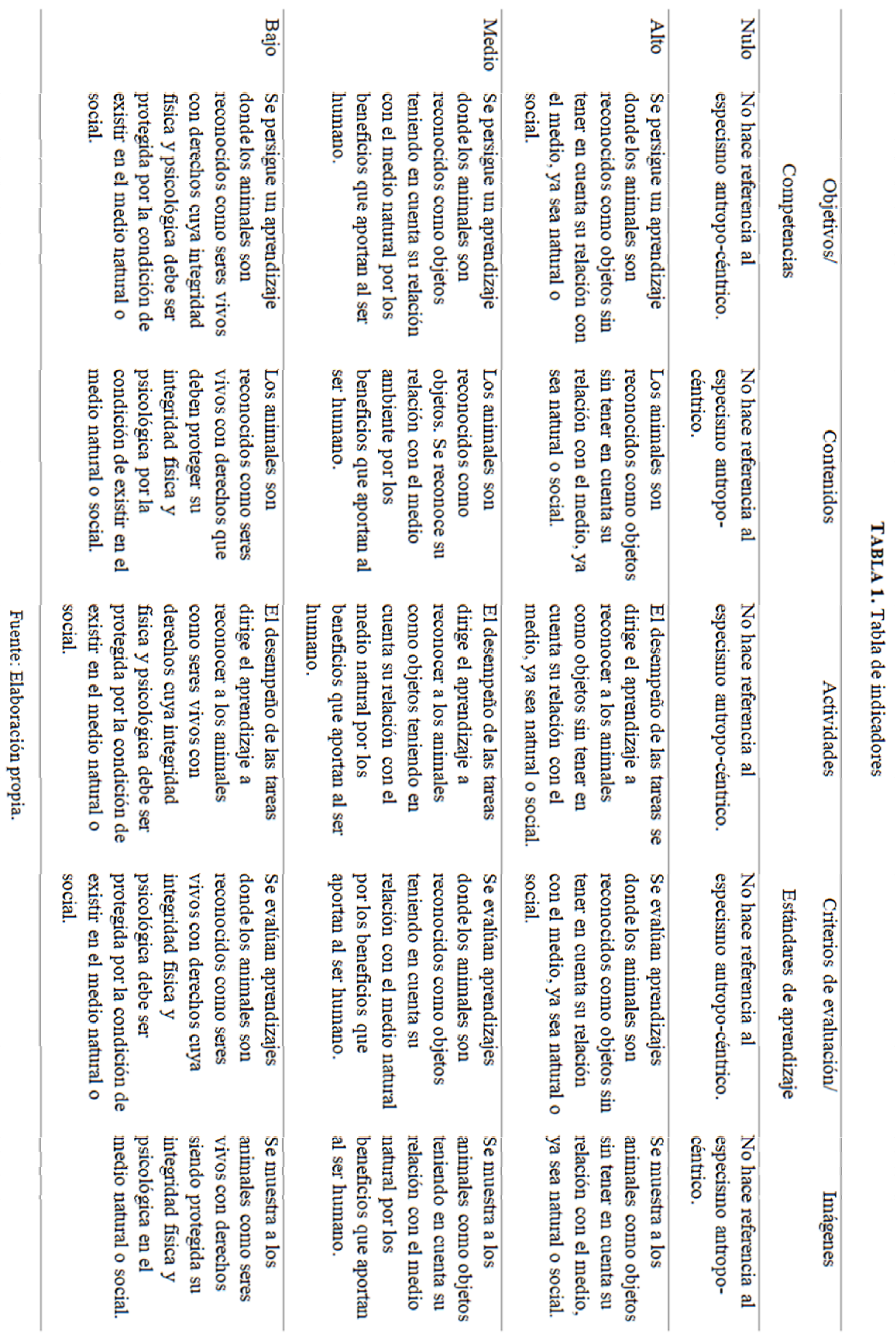


A nivel m acro se analiza el Real Decreto 110 5/2014, de 26 de diciem bre, por el que se establece el currícu lo básico de la Educación Secundaria Obligatoria y del Bachillerato y a nivel autonómico se analiza el Decreto 40/2015, de 15/ 06/2015, por el que se esta blece el currículo de Educación Secundaria Obligato ria y Bachillerato en la Com unidad Autónoma de Castilla-La Mancha. A nivel $\mathrm{m}$ eso se anali zan las program aciones de depart amento del área de Biología y Geología de tres cen tros de Educación Secu ndaria a las que se tuvieron acces o gracias a 1 a colaboración del Equipo Directivo de los centros. A nivel m icro se analizan los libros de texto y el recurso web utilizados en el aula. Se pueden consultar en la tabla 2. Cada lib ro se acompaña del título de la unidad did áctica analizada. A cada recurso se le as igna un nombre para facilitar la lectura de la tabla de resultados. En el libro $4 \mathrm{n}$ o se encuentra unidades didácticas referidas a lo $\mathrm{s}$ animales y su relación con el medio social y natural.

TABLA 2. Recursos didácticos utilizados para el análisis

\begin{tabular}{|c|c|}
\hline Libro 1 & $\begin{array}{l}\text { Sánchez, D. y Cerezo, J.M. (1999). Biología y Geología. E.S.O. } 1^{\circ} \text { Ciclo. Madrid, } \\
\text { España: Santillana, S.A. - Unidad didáctica "El reino animal". }\end{array}$ \\
\hline Libro 2 & $\begin{array}{l}\text { Pedrinaci, E., Gil, C., Carrión, F. y Jimenez, J. (2007). Biología y Geología } \\
1^{\circ} \text { E.S.O. España: Ediciones SM. - Unidad didáctica “Animales. Los Vertebrados". }\end{array}$ \\
\hline Libro 3 & $\begin{array}{l}\text { Pedrinaci, E., Gil, C., Carrión, F. y Jimenez, J. (2008). Biología y Geología } \\
2^{\circ} \text { E.S.O. España: Ediciones SM. - Unidades didácticas "La nutrición en los } \\
\text { animales", "Los ecosistemas: relaciones tróficas" y "Diversidad de ecosistemas". }\end{array}$ \\
\hline Libro 4 & $\begin{array}{c}\text { Canal, S., Mola, J.L. y Suárez, M. (2000). Ciencias de la Naturaleza } 1^{\circ} \text { E.S.O. } \\
\text { Barcelona: Edebé. - No se encuentran unidades didácticas relacionadas con los } \\
\text { animales. }\end{array}$ \\
\hline Libro 5 & $\begin{array}{l}\text { Canal, S., Mola, J.L. y Suárez, M. (2000). Ciencias de la Naturaleza 2E.S.O. } \\
\text { Barcelona: Edebé. - Unidad didáctica "Animales vertebrados". }\end{array}$ \\
\hline Libro 6 & $\begin{array}{l}\text { Duñach, M., Jimeno, A., Saumell, I. y Ugedo, L. (2015). Biología y Geología } \\
1^{\circ} \text { E.S.O. Barcelona: Casals, S.A. - Unidad didáctica "Los animales vertebrados". }\end{array}$ \\
\hline Libro 7 & $\begin{array}{c}\text { Balibrea, S., Álvarez, A., Sáez, A., Reyes, M. y Correa, J. (2005). Ciencias de la } \\
\text { Naturaleza. Biología y Geología 4E.S.O. Madrid: Grupo Anaya, S.A. - Unidad } \\
\text { didáctica "Un mundo de ecosistemas". }\end{array}$ \\
\hline Libro 8 & $\begin{array}{l}\text { Albaledejo, C., Ferrer, A. y Murgadas, F. (1998). Ciencias de la Naturaleza. } \\
\text { Biología y Geología 3E.S.O. España: Oxford University Press. - Unidad didáctica } \\
\text { "Los ecosistemas". }\end{array}$ \\
\hline $\begin{array}{l}\text { Recurso } \\
\text { Web }\end{array}$ & $\begin{array}{c}\text { Aznar, J., Díaz, J., Domingo, E., Leva, M. R., Luengo, L. y De Mier, A. (2009). } \\
\text { Biología y Geología. Instituto Nacional de Tecnologías Educativas y de Formación } \\
\text { del Profesorado. Ministerio de educación, Cultura y Deporte. - Unidad didáctica } \\
\text { "La humanidad y el medio ambiente". }\end{array}$ \\
\hline
\end{tabular}

Fuente: Elaboración propia. 


\section{RESULTADOS}

Para facilitar la lectura de la tabla de resultados se le as igna un número a cada v alor de la tabla de indicadores. El valor "Nulo" se repres enta con un 0, "Alto" con un 1, "Medio" con un 2 y el valor "Bajo" con un 3.

En la tabla 3 se observan los re sultados del análisis del currículo a nivel nacional - Rea 1 Decreto 1105/2014 -, del cual se analiza el Bloque 3: La biodiversidad en el planeta tierra de $1^{\circ}$ y $3^{\circ}$ de ESO y el bloque 3: E cología y medio ambiente de $4^{\circ}$ de ESO; y a nivel de Castilla La Mancha Decreto 40/2015 - se analiza el bloque 3: La biodivers idad en el planeta tierra de $1^{\circ}$ de ESO, el bloque 3: Los ecosistemas de $3^{\circ}$ de ESO y el bloque 2: Ecología y medio ambiente de $4^{\circ}$ de ESO. Se observa un nivel de especism o medio en los ap artados que se encu entran en el currículo Contenidos y Criterios de evaluación/Estándares de aprendizaje -. En el caso del currícu lo a nivel nacional y regional de $4^{\circ}$ de ESO se observan c ontenidos relacionados con el im pacto del ser humano en el medio pero sin relacionarlo de manera directa con la cuestión del bienestar animal. En el currículo de $3^{\circ}$ de ESO de Castilla La Manch a se destaca la importancia de los animales por su importancia como parte de un ecos istema. En cuan to a los objetivos, que $\mathrm{s}$ on los de la etapa de ESO, se obs erva una aproximación a la preocup ación por los seres vivos y su cuidado desde una posición crítica por los hábitos o costum bres sociales. El objetivo se redacta en los siguien tes términos: "Valorar críticamente los hábitos sociales relacionados con la sa lud, el consum o, el cuidado de los seres vivos y el medio am biente, contribuyendo a su conservación y $\mathrm{m}$ ejora". Aunque se califica con un 2, se puede realizar un a lectura donde los seres vivos sean considerados como animales por lo que se podría entender que se tiene en cuenta a los animales como parte de la sociedad y, a priori, señala la necesidad de crítica y reflexión sobre la situación y m ejora del cuidado y conservación de las especies animales.

TABLA 3. Valoración de los elementos del currículo de la LOMCE y de Castilla La Mancha

\begin{tabular}{|c|c|c|c|c|c|c|}
\hline & & $\begin{array}{c}\text { Objetivos/ } \\
\text { Competencias }\end{array}$ & Contenidos & Actividades & $\begin{array}{l}\text { Criterios de } \\
\text { evaluación/ } \\
\text { Estándares de } \\
\text { aprendizaje }\end{array}$ & Imágenes \\
\hline \multirow[t]{2}{*}{$\begin{array}{c}\text { Real Decreto } \\
1105 / 2014 .\end{array}$} & $\begin{array}{l}1 \text { y } 3 \\
\text { ESO }\end{array}$ & 2 & 2 & $0^{*}$ & 2 & $0^{*}$ \\
\hline & $4 \mathrm{ESO}$ & 2 & 2 & $0^{*}$ & 2 & $0^{*}$ \\
\hline $\begin{array}{c}\text { Decreto 40/ } \\
2015\end{array}$ & $1 \mathrm{ESO}$ & 2 & 2 & $0^{*}$ & 2 & $0^{*}$ \\
\hline & $3 \mathrm{ESO}$ & 2 & 2 & $0^{*}$ & 2 & $0^{*}$ \\
\hline & $4 \mathrm{ESO}$ & 2 & 2 & $0^{*}$ & 2 & $0^{*}$ \\
\hline
\end{tabular}

*No existen apartados específicos

Fuente: Elaboración propia.

En la tabla 4 se observan los resultados del an álisis de las program aciones didácticas de la ESO de los departam entos de Biología y Geología de tres centros de se cundaria. La programación didáctica del centro 1 se divide en $1^{\circ}, 3^{\circ}$ y $4^{\circ}$ de ESO. De $1^{\circ}$ de ESO se analiza el bloque 4: La biodiversidad en el plan eta tierra que incluye 5 unidades didácticas; de $3^{\circ}$ de ESO se analiza el 
bloque 3: Los ecosistemas que incluye una unidad didá ctica; de $4^{\circ}$ de ESO se analiza el bloque 2: Ecología y medio ambiente que incluye 3 unidades didácticas. La programación didáctica del centro 2 se divide en $1^{\circ}, 3^{\circ}$ y $4^{\circ}$ de ESO. De $1^{\circ}$ de ESO se analiza el bloque: La biodiversidad en el planeta tierra que consta de 5 unidades didácticas; de $3^{\circ}$ de ESO se analiza el bloque 3: Los ecosistemas que consta de una unidad didáctica; y de $4^{\circ}$ de ESO se analiza el bloque 3: La evolución de la vida que consta de 2 unidades didácticas. La programación didáctica del centro 3 se divide en $1^{\circ}, 3^{\circ}$ y $4^{\circ}$ de ESO. De $1^{\circ}$ de ESO se analiza el tercer trimestre que cuenta con 4 unidades didácticas referidas al ecosistem a y los seres vivos. De $3^{\circ}$ de ES O se analiza el bloque 3: Los ecosistemas que consta de una uni dad; de $4^{\circ}$ de ESO se anali za el bloque 3: Ecología y $\mathrm{m}$ edio ambiente que consta de una unidad.

Se destaca que en la u nidad de $1^{\circ}$ de ESO del centro $1 \mathrm{se}$ realizan prácticas de laboratorio observando seres vivos donde só lo se u tilizan plantas y no anim ales aunque la facilidad para acceder al cadáver de cualquier animal es igual de fácil que el de acceder a una planta por lo que se decide marcar un nivel bajo de especismo en el apartado de actividades. En la unidad de $3^{\circ}$ de ESO se marca un nivel alto ya que en las prácticas de laboratorio se ut iliza el corazón, el riñón y el pulmón de un cerdo. El centro 2 utiliza los objetivos de etapa para el desarrollo de la programación didáctica menos en $4^{\circ}$ de ESO que concreta los obj etivos para el curso y no se e specifica de la misma forma el tratam iento de los anim ales pero se observa un conjunt o de contenidos que persiguen la protección de las distintas especies y la necesidad de protegerlas. Estos contenidos son los siguientes: Reconocimiento del papel de la hu manidad en la extinción de especies; Tom a de conciencia de la necesidad de coexistir pacíficamente con las demás especies que pueblan la Tierra; Estudio de las causas que están provocando la extinción de especies; Valoración de la necesidad de proteger las distintas especies que habitan en el planeta cuya pérd ida sería irreparable. Se califica con un nivel de especis mo bajo ya que se pon e de relieve la neces idad de reflexionar sobre la extinción de las especies y el papel del hombre y se aboga por una actitud reflexiva hacia la convivencia pacífica con otras especies. En el caso de las actividades se pone un 0 ya que no especifican de qué $m$ anera se van a aprender los contenidos relaciona dos con los animales enfocando el aprendizaje con activid ades relacionadas con el $\mathrm{m}$ edio natural y las plantas. En el centro 3, en $1^{\circ}$ de ESO s e califica con un nivel bajo de especism o los objetivos y las competencias ya que los primeros se recogen de los generales de etapa y en las competencias donde se observa el siguiente: Respetar y preservar la vida de los se res vivos de su entorno. Al que se añade dos competencias relacionadas con la com prensión de lo que ocurre alrede dor resolviendo preguntas mediante la ciencia y teniendo en cuenta la acción el ser hum ano en el medio natural. En cuanto a las actividades en $1^{\circ}$ de ESO se s eñala que la anatomía de los animales se es tudiará a través de medios visuales - atlas de anatom ía, revistas sobre la naturaleza, recursos en línea - lo que supone un nivel bajo de especismo. En cambio se observan unos contenidos especistas pues se caracteriza a los animales invertebrados y vertebrados com o una fuente de recursos pa ra los seres hum anos y como un aspecto clave de la dieta humana. En $3^{\circ}$ de ESO no se hace mención a los animales salvo en los objetivos. 
TABLA 4. Valoración de los elementos de las programaciones didáctica de departamento

\begin{tabular}{|c|c|c|c|c|c|c|}
\hline & & $\begin{array}{c}\text { Objetivos/ } \\
\text { Competencias }\end{array}$ & Contenidos & Actividades & $\begin{array}{l}\text { Criterios de } \\
\text { evaluación/ } \\
\text { Estándares de } \\
\text { aprendizaje }\end{array}$ & Imágenes \\
\hline \multirow[t]{3}{*}{ Centro 1} & $1 \mathrm{ESO}$ & 0 & 2 & 3 & 2 & $0^{*}$ \\
\hline & $3 \mathrm{ESO}$ & 0 & 2 & 1 & 2 & $0^{*}$ \\
\hline & $4 \mathrm{ESO}$ & 0 & 2 & 0 & 2 & $0^{*}$ \\
\hline \multirow[t]{3}{*}{ Centro 2} & $1 \mathrm{ESO}$ & 2 & 2 & 0 & 2 & $0^{*}$ \\
\hline & $3 \mathrm{ESO}$ & 2 & 2 & 0 & 2 & $0^{*}$ \\
\hline & $4 \mathrm{ESO}$ & 2 & 3 & 0 & 2 & $0^{*}$ \\
\hline \multirow[t]{3}{*}{ Centro 3} & $1 \mathrm{ESO}$ & 3 & 1 & 3 & 2 & $0^{*}$ \\
\hline & $3 \mathrm{ESO}$ & 2 & 0 & 0 & 0 & $0^{*}$ \\
\hline & $4 \mathrm{ESO}$ & 0 & 2 & 0 & 2 & $0^{*}$ \\
\hline
\end{tabular}

*No existen apartados específicos

Fuente: Elaboración propia.

En la tabla 5 se observan los resultados del an álisis de ocho libros di dácticas y un recurso electrónico. Como ya se ha señalado antes, no se analiza ninguna unidad didáctica el Libro 4. En el caso del Libro 3 se observa la selección de tres unidades didácticas relacionadas con los anim ales. Entre todos los recursos, se ob serva un nivel de especismo $\mathrm{m}$ edio. Los elem entos analizados muestran una relación con los animales donde se id entifica su importancia dentro del medio natural y social por beneficio que recibe el ser humano. Los objetivos analizados se dirigen a la enseñanza de las funciones de los animales en el medio natural o los beneficios que aportan al ser humano. Los contenidos trabajados id entifican a los anim ales dentro sus hábitats, las características comunes entre especies como seres vivos, sus funciones vita les dentro del hábitat. En el $r$ ecurso web se observa las siguientes afirmaciones El ser humano descubre la agricultura y la ganadería para su alimentación y beneficio y El desarrollo sostenible es la forma de actuación del ser humano con el entorno que le permite disfrutar del planeta Tierra sin ponerlo en peligro para las generaciones futuras donde se observa el carácter especista y antropocéntrico ya que sitúa al ser hum ano en el centro de la relación y explotac ión del medio y los anim ales eludiendo la im portancia del medio para el resto de ani males no humanos o el interés de los animales en tener una vida plena libre de dolor. En un apartado se trata la extinción de los animales señalando dos ejemplos pero sin mayor profundidad que la $\mathrm{m}$ era descripción del hecho eludi endo la importancia de los animales para la sostenibilidad del plan eta. Las actividades contemplan los contenidos trabajados en el tem a así como los criterios de evaluación. Las im ágenes utilizadas muestran a los anim ales en su hábitat, completando la información de los contenidos y los espacios que ocupan los anim ales para beneficio del ser humano como piscifactorías o espacios de ganadería intensiva. 
TABLA 5. Valoración de los elementos de cada recurso

\begin{tabular}{|c|c|c|c|c|c|}
\hline & $\begin{array}{c}\text { Objetivos/ } \\
\text { Competencias }\end{array}$ & Contenidos & Actividades & $\begin{array}{l}\text { Criterios de } \\
\text { evaluación/ } \\
\text { Estándares de } \\
\text { aprendizaje }\end{array}$ & Imágenes \\
\hline Libro 1: El reino animal & 2 & 2 & 2 & 2 & 2 \\
\hline $\begin{array}{c}\text { Libro 2: Animales. Los } \\
\text { Vertebrados }\end{array}$ & 2 & 2 & 2 & 2 & 2 \\
\hline $\begin{array}{l}\text { Libro 3: La nutrición en } \\
\text { los animales }\end{array}$ & 2 & 2 & 2 & 2 & 2 \\
\hline $\begin{array}{l}\text { Libro 3: Los ecosistemas: } \\
\text { relaciones tróficas }\end{array}$ & 2 & 2 & 2 & 2 & 2 \\
\hline $\begin{array}{l}\text { Libro 3: Diversidad de } \\
\text { ecosistemas }\end{array}$ & 2 & 2 & 2 & 2 & 2 \\
\hline $\begin{array}{l}\text { Libro 5: Animales } \\
\text { vertebrados }\end{array}$ & 2 & 2 & 2 & 2 & 2 \\
\hline $\begin{array}{l}\text { Libro 6: Los animales } \\
\text { vertebrados }\end{array}$ & 2 & 2 & 2 & 2 & 2 \\
\hline $\begin{array}{l}\text { Libro 7: Un mundo de } \\
\text { ecosistemas }\end{array}$ & 2 & 2 & 2 & 0 & 2 \\
\hline Libro 8: Los ecosistemas & 2 & 2 & 2 & 0 & 2 \\
\hline $\begin{array}{c}\text { Recurso Web: La } \\
\text { humanidad y el medio } \\
\text { ambiente }\end{array}$ & 1 & 2 & 0 & 0 & 2 \\
\hline
\end{tabular}

Fuente: Elaboración propia.

\section{DISCUSIÓN Y CONCLUSIONES}

En general, en los docum entos analizados, en el currículo p rescriptivo a nivel nacio nal y de comunidad autónoma en Castilla La Mancha, en las programaciones didácticas de departamento de Biología y Geología y en los libr os didácticos y recurso web se observa una posición especista media, esto es, lo $\mathrm{s}$ animales se consideran objetos pero se es tablece una rela ción entre la importancia de cada especie y su aportación medio natural y al ser humano según sus características - funciones y relaciones de los anim ales en su medio, características, anatomía, etc. - lo qu e justifica la condición de objet o de los anim ales reproduciendo la relación de dominación del ser humano sobre los anim ales. Esto se relaciona con los datos obtenidos por Pedersen (2004) en su estudio piloto en una escuela de Primaria en Suecia.

En cuanto al objetivo de etapa que se aproxim a a la consid eración del bienestar animal y la necesidad de crítica sobre su situación en la sociedad, se puede entender como un objetivo potente para introducir una perspectiva antiespecista mediante el debate sobre la situación de los animales 
desde la posición del especism o antropocéntrico puesto que viene reflejado en el currículo oficial para todo el estado. Se observan program aciones didácticas con elementos contradictorios como en el caso de $1^{\circ}$ de ESO donde los contenidos y la $\mathrm{s}$ actividades presentan un nivel bajo de especismo pero en los contenidos se trata a los animales cómo bienes de consumo humano.

En los documentos analizados se observa una cantidad significativa de elementos donde no se menciona a los anim ales de $\mathrm{m}$ anera explícita cuando se supone un aspecto im portante en el desarrollo de los contenidos de apre ndizaje. Esto puede ocurrir por la falta de importancia que se le otorga a la figura de los anim ales con sus car acterísticas, relaciones, funciones e im portancia singular dentro del estudio de las ciencias naturales. Al igual que el trabajo de Mazas y Fernández (2016) se identifican elementos que justifican la importancia de cuidar y asegurar el bienestar de los animales por la aportación posterior a las nece sidades del ser hum ano y su contribución a la sostenibilidad del medio natural pero no por el reconocimiento de los anim ales como individuos con derecho a una vida plena. Esta perspectiva del bienestar animal mide la calidad de vida de los animales obviando las consideraciones éticas y morales (Alonso, 2016).

Es necesario superar los contenid os normalizados en el currículo qu e ocultan form as de especismo desarrollando estrategias altern ativas de aprendizaje que dirija a lo s estudiantes al desarrollo de marcos de representación y compre nsión de la realidad donde se reconozca a lo $\mathrm{s}$ animales cómo individuos con el derecho de vivir una vida que merezca ser vivida en relación a sus capacidades e intereses, que suponga el cultivo de valores que se alejen de posiciones racistas, patriarcales, clasistas o capacitis tas (Vázquez y Sánchez, 2017) h acia una educación m ás humana (Renk, 2014) y que favo rezca los vínculos entre los seres humanos, reconocidos entre ellos como sujetos cuya vida $\mathrm{m}$ erece ser vi vida con dignidad, y con el $\mathrm{m}$ edio natural, reconocido cóm o el espacio que sustenta las relaciones que posibilitan la vida.

\section{Posibles LÍNEAS De inVESTigación}

El tratamiento del especismo dentro del currículo escolar y en particular el análisis cualitativo del contenido desde la perspectiva especis ta no es un tem a con un soporte científico am plio. Se espera que esta aportación suponga una base para continuar indagando en el campo de estudio sobre la educación especista oculta en el currícu lo, en los recursos didácticos y en el discurso educativo en la etapa de secundaria pero tam bién en infantil, primaria, a nivel univers itario y en centro de formación fuera de la enseñanza reglada, en la formación en asociaciones, organizaciones y centros culturales.

En esta línea se formulan posibles líneas de investigación enfocadas a la etapa de secundaria. El siguiente paso sería com probar como una educación especista influye en al aprendizaje de los estudiantes de la ESO y Bachiller e n el desarrollo de un co njunto de conocimientos y habilidades imprescindibles de carácter prope déutico para el área de Biologí a y Geología pero tam bién desde una perspectiva interdisciplinar donde se vea la calidad de los procesos relacionados con el razonamiento, reflexión y crítica. Otra línea d e investigación puede centrars e en el anális is del currículo oculto en cuanto a la construcción de una cultura especista.

\section{Referencias}

Albaledejo, C., Ferrer, A. y Murgadas, F. (1998). Ciencias de la Naturaleza. Biología y Geología $3^{\circ}$ E.S.O. España: Oxford University Press.

Alonso, M. (2016). La ciencia del Bienestar Anim al. En R. Ra mírez, M. Ramírez y E. Escandón (Eds.), La paradoja del Bienestar Animal (pp. 9-19). México: Editorial Lider. 
Aznar, J., Díaz, J., Dom ingo, E., Leva, M. R., Luengo, L. y De Mier, A. (2009). Biología y Geología. Madrid: Instituto Nacional de Tecnología $\mathrm{s}$ Educativas y de Form ación del Profesorado. Ministerio de educación, Cultura y Deporte.

Balibrea, S., Álvarez, A., Sáez, A ., Reyes, M. y Correa, J. (2005). Ciencias de la Naturaleza. Biología y Geología $4^{\circ}$ E.S.O. Madrid: Grupo Anaya, S.A.

Canal, S., Mola, J.L. y Suárez, M. (2000). Ciencias de la Naturaleza $1^{\circ}$ E.S.O. Barcelona: Edebé.

Canal, S., Mola, J.L. y Suárez, M. (2000). Ciencias de la Naturaleza $2^{\circ}$ E.S.O. Barcelona: Edebé.

Ceballos, G. y Ortega-Baes, P. (2011). La sexta extinción: la pérdida de especies y poblaciones en el Neotrópico. En J. Simonetti y R. Dirzo (Eds.), Conservación Biológica: Perspectivas de Latinoamérica (pp. 95-108). Chile: Editorial Universitaria.

Decreto 40/2015, de 15/06/2015, por el que se es tablece el currículo de Educación Secundaria Obligatoria y Bachillerato en la Comunidad Autónoma de Castilla-La Mancha.

Díaz, M. (2015). El miembro no humano de la familia: las mascotas a través del ciclo vital familiar. Revista Ciencia Animal, 9, 83-98.

Dorado, D. y Horta, O. (2014). Cambio de paradigm a: un análisis bibliográfico de la literatura reciente en ética animal. Dilemata, 15, 103-112.

Duñach, M., Jimeno, A., Saumell, I. y Ugedo, L. (2015). Biología y Geología $1^{\circ}$ E.S.O. Barcelona: Casals, S.A.

Fernández, F. (2002). El análisis de contenido com o ayuda metodológica para la investigación. Revista de Ciencias Sociales, 2(96).

Gómez, L., Atehortua, C. y Orozco, S. (2007). La influencia de la s mascotas en la vida hum ana. Revista Colombiana de Ciencias Pecuarias, 20, 377-386.

González, M. y Landero, R. (2011). Diferencias en Estrés Percibido, Salud Mental y Física de acuerdo al Tipo de Relación Humano-Perro. Revista Colombiana de Psicología, 20(1), 75-86.

Horta, O. (2009). El antropocentrismo y el argumento de los vínculos emocionales. Dilemata, 1, 113.

Horta, O. (2010). W hat is Speciesism? The Journal of Agricultural and Environmental Ethics, 23, 243-266.

Hugues, B., Álvarez, A., Lerdón, L., Mendoza, M., Castelo, L. y Domínguez, E. (2014). Percepción de los beneficios de la tenencia de anim ales de compañía en pacientes con enf ermedades cardiovasculares. CorSalud, 6(1), 56-62.

Jukes, N. y Chiuia, M. (2006). Form Guinea Pig to computer mouse. England: InterNICHE.

Latouche, S. y Harpagés, D. (2011). La hora del decrecimiento. Barcelona: Octaedro.

Leyton, F. (2010). Literatura básica en torno al especismo y los derechos de los anim ales. Revista de Bioética y Derecho, 19, 14-16.

Low, P. (2012). The Cambridge Declaration on Consciousness. Recuperado de http://fcmconference.org/img/CambridgeDeclarationOnConsciousness.pdf

Mayer, J. D. y Salovey, P. (1997). What is emoti onal intelligence? En P. Salovey y D. J. Sluyter (Eds.), Emotional development and emotional intelligence: Educational implications (pp. 334). New York: Harper Collins.

Mazas, B. y Fernández, R. (2016). El concepto de bienestar animal en el currícu lo de Secundaria Obligatoria y en los libros de texto de Ciencias. Revista Eureka sobre Enseñanza y Divulgación de las Ciencias, 13(2), 301-314.

Mendez, A. (2014). El movimiento animalista en la cultura digital. Un estudio exploratorio sobre los colectivos antiespecistas y la lucha por los derechos animales. Congreso PreALAS Calafate. Universidad Nacional de la Patagonia Austral.

Ministerio de Agricultura, Alim entación y Medio Ambiente (2015). Análisis y caracterización del sector de los animales de compañía. Informe de resultados. Madrid. Recuperado de http://colvet.es/sites/default/files/201602/Informe $\% 20$ sobre $\% 20$ animales $\% 20 \mathrm{de} \% 20$ compan $\% \mathrm{CC} \% 83 \mathrm{i} \% \mathrm{CC} \% 81 \mathrm{a} . \mathrm{pdf}$ 
Ministerio de Agricultura y Pesca, Alimentación y Medio Am biente (2017). Bienestar Animal. Recuperado de http://www. mapama.gob.es/es/ganaderia/temas/produccion-y-mercadosganaderos/bienestanimal/

Ministerio de Medio A mbiente, Medio Rural y Urbano (2010). Legislación relativa a protección animal (Bienestar animal). Volumen II: Comunidades Autónomas. Madrid: Subdireccion General De Explotaciones y Sistemas De Trazabilidad.

Pedersen, H. (2004). Schools, Speciesism, and Hidden Curricula: The Role of Critical Pedagogy for Humane Education Futures. Journal of Futures Studies, 8(4), 1-14.

Pedrinaci, E., Gil, C., Carrión, F. y Jim enez, J. (2007). Biología y Geología 1 ${ }^{\circ}$ E.S.O. España: Ediciones SM.

Pedrinaci, E., Gil, C., Carrión, F. y Jim enez, J. (2008). Biología y Ge ología $2^{\circ}$ E.S.O. Espa ña: Ediciones SM.

Real Decreto 1105/2014, de 26 de diciem bre, por el que se es tablece el currículo básico de la Educación Secundaria Obligatoria y del Bachillerato.

Renk, M. (2014). Teaching Compassion: Humane Education in Early Childhood. USA: Springer.

Sánchez, D. y Cerezo, J.M. (1999). Biología y Geología. E.S.O. 1ºiclo. Madrid, España: Santillana, S.A.

Valencia, A. y Vázquez, R. (2015). Pensar más allá de la especie. La creciente relevancia de los “Animal Rights Debates” en la Teoría Política contemporánea. XII CONGR ESO DE AECPA. Madrid.

Vázquez, R. y Sánchez, M. (2017). Antropo (andro) centrismo y especie. Ideología y naturalización del especismo en tiempos liberales. Eunomía. Revista en Cultura de la Legalidad, 12, 26-38.

Villalba, T. (2017). Código de protección y bienestar animal. Madrid: Agencia Estata 1 Boletín Oficial del Estado. Recuperado de http://www.boe.es/legislacion/codigos/codigo.php?id=204

Villalba, T. (2015). 40 años de bienestar animal: 1974-2014. Guía de la legislación comunitaria sobre bienestar animal. Madrid: Ministerio de Agricultura, Alimentación y Medio Ambiente.

Rowlands, M. (2016) Are animals persons? Animal Sentience, 10(1).

Zamarra, M. P. (2002). Terapia asistida por anim ales de compañía: bienestar para el ser hum ano. Centro de salud, 10(3), 143-149.

\section{CÓMO CITAR ESTE ARTÍCULO}

González Berruga, P. y González Berruga, M. A. (2018). Análisis del discurso especista antropocéntrico en la Educació n Secundaria Obligatoria. Didáctica de las ciencias experimentales y sociales, 34, 63-76. DOI: 10.7203/DCES.34.10944. 
